\title{
Genetic counselling for infertile men of known and unknown etiology
}

\author{
Riyana Babul-Hirji ${ }^{1,2}$, Ruqayya Hirji ${ }^{3}$, David Chitayat ${ }^{1,3}$ \\ ${ }^{1}$ Division of Clinical and Metabolic Genetics, Department of Pediatrics, The Hospital for Sick Children, University of Toronto, Toronto, ON, \\ Canada; ${ }^{2}$ Department of Genetic Counselling, The Hospital for Sick Children, University of Toronto, Toronto, ON, Canada; ${ }^{3}$ The Prenatal \\ Diagnosis and Medical Genetics Program, Department of Obstetrics and Gynecology, Mount Sinai Hospital, University of Toronto, Toronto, ON, \\ Canada \\ Contributions: (I) Conception and design: All authors; (II) Administrative support: None; (III) Provision of study materials or patients: None; (IV) \\ Collection and assembly of data: None; (V) Data analysis and interpretation: None; (VI) Manuscript writing: All authors; (VII) Final approval of \\ manuscript: All authors. \\ Correspondence to: Dr. David Chitayat. The Toronto Hydro Generation Building, 700 University Avenue, 3rd Floor, Toronto, Ontario M5G 1Z5, \\ Canada. Email: david.chitayat@sinaihealth.ca.
}

\begin{abstract}
Of the couples trying to conceive (had frequent, unprotected sexual intercourse for a year or longer) $15 \%$ will experience infertility with the annual incidence of infertility estimated at 1.2 couples per 1,000 total in the general population. Male factors contribute to over $50 \%$ of the cases with $7 \%$ of the male population experiencing infertility. Not being able to conceive a child is emotionally traumatic and frustrating and can affect the person's self esteem and the couple's relationship. Major progress has been achieved in identifying the etiology of male infertility and especially the genetic causes. However, in about $40 \%$ of the male infertility cases, the etiology remains unknown and both the diagnosis and/or treatment are a challenge. Genetic testing to determine the underlying genetic cause of infertility is not $100 \%$ and genes involved are still being discovered. Consequently, negative genetic test results do not rule out a genetic cause. Thus, genetic counselling should include information regarding the genetic etiology, if known, and the treatment options available. Furthermore, when the infertile couple/male is seeking assisted reproductive technology (ART) using intracytoplasmic sperm injection (ICSI), genetic counselling should include information regarding the risk of transmitting the genetic disorder, causing the male infertility, to the offspring. Therefore, the provision of genetic counselling is an integral component in the investigation and treatment of male infertility. This article will discuss the genetic counselling approach in cases with male infertility.
\end{abstract}

Keywords: Genetic counselling; infertility; male; genetics; oligospermia; azoospermia; obstructive azoospermia (OA); non-obstructive azoospermia (NOA)

Submitted Dec 04, 2019. Accepted for publication Nov 10, 2020.

doi: 10.21037/tau-2019-gcmi-09

View this article at: http://dx.doi.org/10.21037/tau-2019-gcmi-09

\section{Introduction}

Of the couples trying to conceive, $8-20 \%$ will experience infertility and the annual incidence of infertility is estimated at 1.2 couples per 1,000 total in the general population (1). Male factors contribute to over $50 \%$ of the cases with infertility (2) and overall, $7 \%$ of the male population experience infertility. Male infertility can be extrinsic and caused by environmental exposures such as infections, medication and heat or it can be intrinsic and caused by a variety of conditions, many of them, genetic (3). The intrinsic causes of male infertility can be divided into quantitative defects, responsible for $70 \%$ of male infertility and caused by abnormalities in sperm production and qualitative defects, responsible for about $30 \%$ of the known causes (Figure 1). The quantitative causes can be divided into 


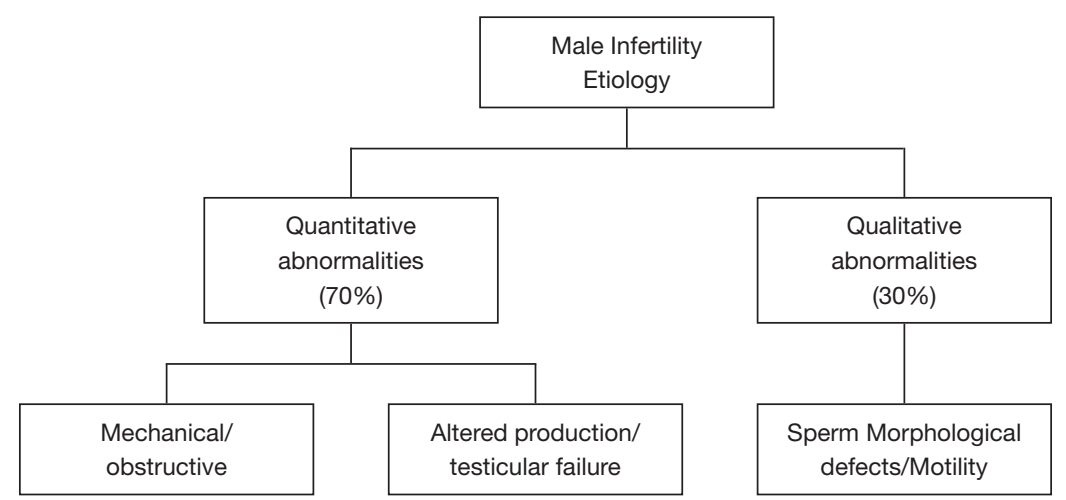

Figure 1 Male infertility—genetic etiologies.

mechanical/obstructive causes, as seen in conditions such as cystic fibrosis (CF), ciliary dysfunction and spermatic cord dysfunction and impaired production, as in chromosome abnormalities such as Klinefelter syndrome and endocrine dysfunction such as in hypogonadotropic hypogonadism (4). Categorization by obstructive azoospermia (OA) with normal testicular volume (testicular volume $20 \mathrm{~mL}$ ) and follicle-stimulating hormone (FSH) (1-8 IU/mL) or nonobstructive azoospermia (NOA) with mall, soft testes and increased FSH is critical since genetic testing and counselling differs (Figure 2) (3). Once the semen analysis is done and non-genetic causes are ruled out, investigations should be directed according to the findings. In cases with quantitative problems, genetic analysis should include microarray analysis and $\mathrm{Y}$ chromosome panel looking for submicroscopic deletions at $\mathrm{Yq}$ of the AZFa, ZFb and AZFc loci, endocrine studies looking for abnormalities along the hypothalamic-pituitary axis and DNA analysis for pathogenic variants in the CFTR gene. When a qualitative defect is identified, DNA analysis for causative genes such as DPY19L2, AURKC, DNAH1 and other genes associated with primary ciliary dyskinesia should be analyzed. In general, in about $40 \%$ of the cases of male infertility, the cause remains unknown. Genetic causes can be identified only in approximately $15 \%$ of the cases (3). For further information regarding the etiological investigation and the clinical findings associated with specific etiologies, please refer to the other articles in this issue. This article will provide an overview of the genetic counselling approach for men with infertility of known and unknown genetic cause.

\section{Genetic counselling in male infertility}

Genetic counselling "is the process of helping people understand and adapt to the medical, psychological, and familial implications of the genetic contributions to disease.

This process integrates:

(I) Interpretation of family and medical histories to assess the chance of disease occurrence or recurrence;

(II) Education about inheritance, testing, management, prevention, resources and research;

(III) Counselling to explain the options available and to promote informed choices and adaptation to the risk or condition." (5).

Genetic counselling is an integral component of the assessment and treatment of men presenting with infertility. It has a major role in educating the patient/couple about possible etiologies, testing options and recurrence risks as well as providing psychosocial support by cultivating a culture of empathy and trust. Other factors such as coping styles need to be considered during the genetic counselling encounter, including assessing for any underlying psychological factors. Occasionally, a diagnosis of a genetic/chromosomal disorder is made in the pediatric setting, where in a male child, infertility is expected to be part of the clinical manifestations after puberty. Other times, the diagnosis comes to light in adulthood because of the work-up of infertility. The timing of disclosure of infertility is important in the genetic counselling process as the approach taken is guided by this knowledge. Emotions and psychological reactions may vary depending on whether the diagnosis is new, as in the adult male, or whether the disclosure occurred over time in childhood and thus was included as part of the transition counselling to adult health. Genetic counselling is crucial in helping the patient/couple or family understand the basis of his/her/their condition, provide them with information associated with the condition including options available, provide support, and empower 


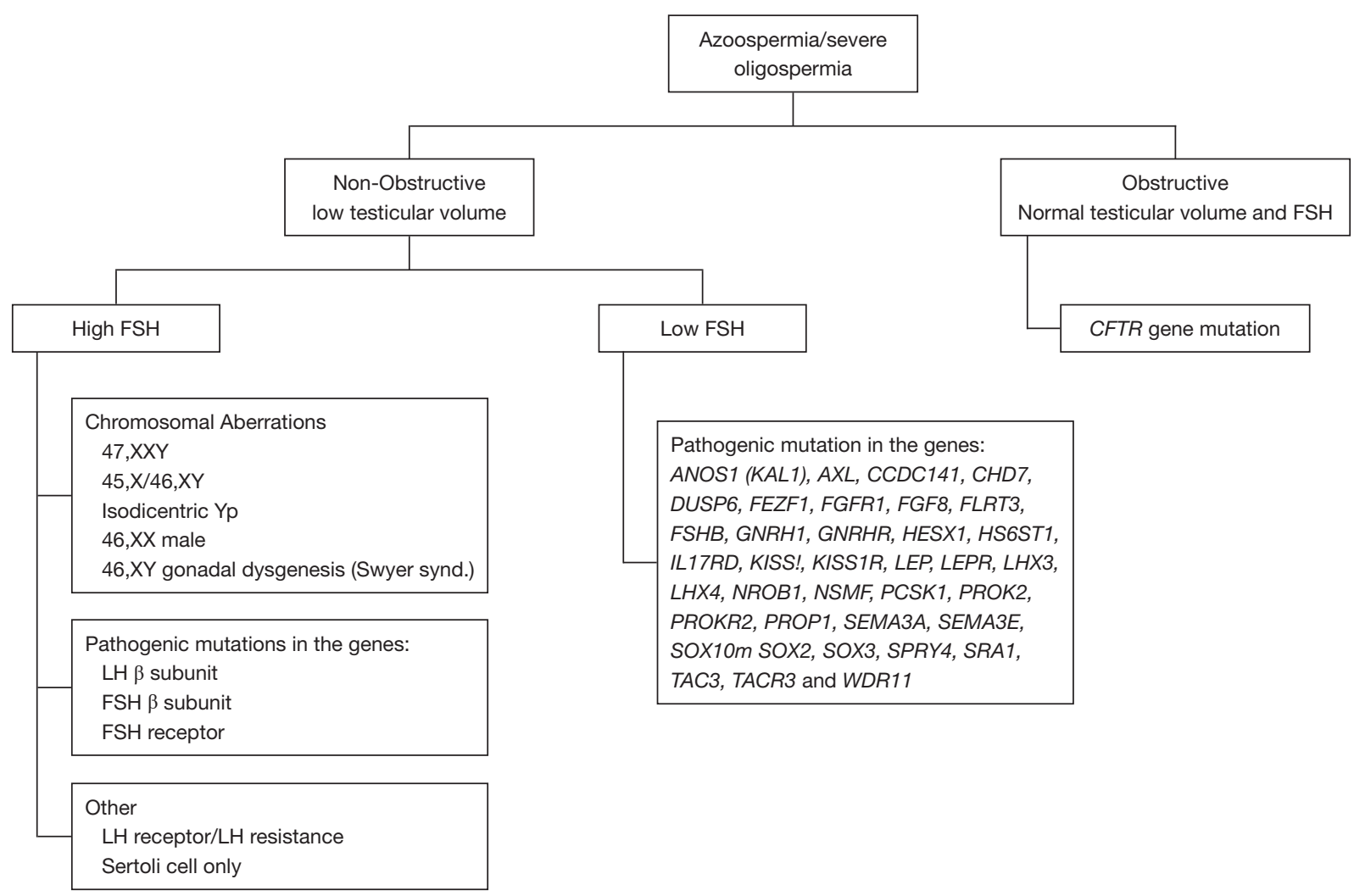

Figure 2 Azoospermia and severe oligospermia-non-obstructive and obstructive etiologies.

them to advocate for him/themselves or their family.

Ideally, the genetics health care provider is a member of the reproductive medicine team. Patients can be referred for genetic counselling for discussion of results, already having had the diagnostic work-up for male infertility performed by another member of the reproductive team, such as the urologist. As part of the genetic counselling, a detailed three generation pedigree is obtained and targeted for a family history of infertility, recurrent miscarriages, stillbirths, consanguinity, intellectual disability, genetic conditions, birth defects and ethnic background. The couple/male client are informed of the results followed by a detailed discussion of the underlying genetics, risk of recurrence, reproductive options, options available to prevent the risk of recurrence, risks associated with each option, and supportive counselling.

\section{Genetic counselling at different stages of investigation}

There are mainly three possible stages when the couple/ male patient is seeking genetic counselling/referral for genetic counselling following the finding of an abnormal semen analysis:

(I) Genetic counselling prior to genetic investigation;

(II) Genetic counselling following an identified etiology;

(III) Genetic counselling when the etiology could not be delineated;

(IV) Communicating the information to the patient/ couple.

\section{Genetic counselling prior to genetic investigation}

In a male where genetic testing to delineate the possible etiology has not been done and thereby the underlying genetic cause is not known, the genetic counselling approach would follow many of the same facets as previously mentioned, but with the addition of pre-test counselling. Pre-test counselling would cover aspects such as possible results scenario and what the client/couple would do in each possible scenario (i.e., anticipatory counselling), 
how the results could impact other family members, as well as limitations of the test.

\section{Genetic counselling following an identified etiology}

Given the advances in assisted reproductive technologies (ART), men with infertility may have the option to have their own biological children via IVF and intracytoplasmic sperm injection (ICSI). In this case, there may be implications for his children.

\section{Male infertility associated with chromosome abnormalities}

If the cause of infertility is deletion/microdeletion of the long arm of chromosome $\mathrm{Y}$ as seen in isodicentric $\mathrm{Yp}$, this Y-chromosome microdeletion will be passed to each of his sons and thus his/their son will present with infertility. Sometimes, according to the condition passed, the risk to future children may be more than only the risk of infertility. If the cause of the infertility in the male patient is a balanced translocation for example, then there may be an increased risk of passing on an unbalanced chromosome translocation to future offspring of both sexes who could present with medical/intellectual disability.

Males with Klinefelter syndrome (i.e., 47,XXY or $47, \mathrm{XXY} / 46, \mathrm{XY})$, have gonadal failure affecting both spermatogenesis and testosterone production and are thus both azoospermic and hypomasculanized. However, successful recovery of spermatozoa from some 47,XXY males, used subsequently in ICSI procedures, has been reported in the literature. A review of the current literature documents conflicting reports regarding the risk of aneuploidy in the offspring of males with $47, \mathrm{XXY}$, conceived by $\operatorname{ICSI}(1,2)$. However, from case reports available to date, this risk is predicted to be low (3-6). Genetic counselling should be provided to these couples to discuss the available information including their risk of fetal aneuploidy and the available options for preimplantation and prenatal diagnosis in addition to providing support and reassurance where indicated.

\section{Male infertility associated with congenital bilateral absence of vas deference (CBAVD)}

In $1-2 \%$ of infertile men the cause is mutations in the cystic fibrosis transmembrane conductance regulator (CFTR) gene which cause congenital bilateral absence/dysfunction of the vas deferens (CBAVD). In these cases genetic testing reveals heterozygous or homozygous pathogenic variant(s) in the CFTR gene. Depending on his partner's carrier status and mutation results, there is a potential risk to have children with the more clinically severe form of cystic fibrosis (CF) with pulmonary and pancreatic involvement. Offering CF carrier testing to the partner is essential in these cases so that they are aware of their risks, if any, as a couple. The risk is predicted to be low if the partner is negative on sequencing and deletion/duplication testing of the CFTR gene. However, if the partner returns a carrier, then depending on the combination of their variants together, they could be at risk to have a male with congenital absence of the vas deferens, or a child with the severe form of CF. In a study done by Fitzpatrick et al., 1996, men who presented for genetic counselling with CBAVD and CF testing were less concerned about the health implications associated with $\mathrm{CF}$ then their reproductive potential. In the above examples, genetic counselling, while respecting patient autonomy and choices, would involve a detailed discussion of the risk of recurrence, the spectrum of clinical manifestations in future children (where applicable), explore what this means to the male client/couple, review options available and offer relevant patient resources/support.

\section{Preimplantation and prenatal genetic diagnosis}

Preimplantation genetic testing (PGT), to prevent the risk of having an affected offspring, (e.g., for CF), maybe an option. The use of PGT for chromosome abnormalities (PGT-A) or single gene disorders (PGT-D), has generated considerable discussion regarding the implications of PGT, sex selection, safety of embryonic manipulation and should be included in the genetic counselling.

PGT consists of the following steps (I) IVF/ICSI, followed by (II) a biopsy of embryonic cells to be tested, usually trophectoderm cells, and (III) PGT (A or D) for the selective transfer of an unaffected embryo. PGT has been applied for some 25 years and thousands of 'PGDbabies' have been born so far. The reliability of the genetic tests used is very high; however, there are still some safety and accuracy concerns (especially related to embryos with chromosome mosaicism). The current knowledge suggests that the procedure might decrease the pregnancy rate but is not associated with an increased incidence of congenital abnormalities/developmental delay in children thus conceived (6-8). However, the possibility of inaccuracy in the diagnosis and the fact that PGT-A does not provide the same chromosome resolution as microarray analysis 
done on chorionic villus sampling (CVS) and amniocentesis should be discussed in the counselling ssession and the option of CVS/amniocentesis and the very small risk for a miscarriage associated with the procedures $v s$. the benefit has to be explained. The possibility that there may be no unaffected embryo available for transplantation should also be discussed in advance to avoid un-realistic expectations. PGT-A for female sex selection, when the genetic abnormality is Y-linked, may be justified and should be discussed with the patient/couple. Through genetic counselling, the client/couple is empowered to make informed decisions in keeping with their cultural and ethical values as well as religious beliefs. This discussion should be non-judgmental and follow a shared decision making approach (9).

The option of prenatal diagnosis by CVS and amniocentesis should also be discussed as well as the timing and risk for miscarriage associated with each of the procedure.

\section{Implications for other family members}

When a genetic diagnosis has implications to other family members (e.g., CF and increased risk for being carriers or other single gene disorders and possible familial chromosome rearrangement), genetic counselling would provide recommendations to the client/couple as to how they could inform other at-risk individuals in the family. There may be barriers to communicating this information to other at-risk family members such as loss of contact. Moreover, there could be feelings of stigma and guilt of having an underlying genetic condition compounded by wanting to keep private their reproductive issues and avoid discussing it with other family members. Genetic counselling would encourage discussion of the relevance of communicating the results to other family members, and to help facilitate their decision-making process. If the client/couple chooses not to disclose, then the privacy and autonomy of the patient is maintained over the duty to disclose to at-risk relatives $(10,11)$.

\section{Genetic counselling when the etiology cannot be delineated}

When genetic testing cannot reveal an underlying cause, the client/couple may understandably feel frustrated. Genetic counselling would focus on providing psychological counselling in a supportive environment (12). The couple should be informed of the limitations of genetic testing, emphasizing that although the investigations are negative, this does not rule out an underlying genetic cause of the male infertility. Thus, if the client/couple are considering IVF, there could be a risk of recurrence in their children, mainly in males, but this risk is not known. Thus, the IVF is done solely for conception, although PGT-A and sex selection could be performed. Should the patient/couple wish to avoid the risk of having an affected child, using a donor sperm in the IVF should be discussed as an option. Some families decide to proceed with intrafamilial or sperm donation from a known donor. In this case, the client/couple would need to be made aware of the potential medical risks, the emotional issues that could negatively impact familial relationships, as well as the possible social impact on future offspring (13).

\section{Communicating the information to the patient/couple}

Regardless of whether an underlying genetic cause is known or not known, communicating the necessary and relevant information to the client/couple would be done in keeping with their expectations, processing abilities (14), and in a culturally sensitive manner to promote trust (15).

The literature on the psychological and social experiences of men with infertility are limited. However, the available data suggest that what men experience and how they cope is different from women presenting with the same situation. For instance, men prefer to share their emotions with and receive support from their reproductive health care team versus mental health professionals or even friends (16). The diagnosis of male factor infertility may result in more secrecy about the diagnosis to the extent that sometimes the female partner informs her relatives/friends that she is the cause of the infertility $(17,18)$. Furthermore, male factor infertility is more strongly associated with sexual disorders than female factor infertility (19). Media reports on "the sperm decline" tend to construct stereotypical masculinity and conflate male infertility with impotence (20), although it is common knowledge that infertility has no impact on the physical aspects of potency. In men affected with infertility, the unfulfilled desire for a child and a sexual dysfunction are often believed to be synonymous [the "fertility-virility linkage" (21-25)]. In a Danish questionnaire study on 210 men undergoing ICSI treatment, $37 \%$ of the participants stated that the reduced sperm quality (and not the ICSI procedure per se) affected their perception of masculinity (26). With regards to levels of depression and anxiety in infertile males versus controls, other than at initial investigations, diagnosis, and subsequent 
treatment, the overall prevalence of clinically significant presentation of depression and anxiety is not higher in men with infertility than in the general population. It is thought that men may be able to separate what they are feeling and compartmentalize it so as not to impact their professional lives and be a source of social support for their partners (16). However, given the evidence that men who are "socially isolated, have an avoidant style and appraise stressful events as overwhelming are particularly vulnerable to more severe anxiety" (16), it is important from a genetic counselling perspective to be cognizant of the potential psychological impact of infertility to males and assess from the onset their emotional well-being and coping mechanisms. In contrast, as an infertile couple, the rates of symptoms of anxiety (24.2\%) and depression (20\%) have been noted to be higher than corresponding controls $(13.7 \%$ and $9.5 \%$ respectively) (27). Males with infertility and their partner navigate many emotional reactions in their journey to achieve a pregnancy. Factors such as financial burden of treatment, putting a hold on professional or personal goals while treatment is on-going, feeling defeated at failed attempts of achieving successful pregnancies, the moral and ethical predicaments that may arise in the discussions leading up to treatment or as part of the treatment process itself-all of these can precipitate the onset of psychological symptoms such as depression and anxiety, as well as marital discord. In addition, diagnosis and initiation of treatment are associated with elevated infertility-specific anxiety and unsuccessful treatment can lead to a state of lasting sadness (16). Genetic counselling, by using a clientcentred or person-centered approach, should aim to assess and address any psychological reactions. In this way, the genetics health care provider would help the couple identify any underlying emotions, including how each member of the couple may be coping/feeling differently. By identifying the psychological issues and the interpersonal dynamics of the couple, the couple can explore appropriate strategies or interventions to reduce their stress and emotional reactions. If the genetics health care provider feels that the underlying psychological issues are complex or acute, a referral to a psychologist/psychiatrist would be suggested and made with the client's/couple's consent.

\section{Conclusions}

The genetic factors involved in male infertility are just beginning to be delineated and understood. With genomic medicine and genomic sequencing, many more factors leading to or contributing to male infertility will come to light. From lessons learnt in other areas of genetics using genome wide studies, such testing will result in complex data requiring thorough analysis and interpretation. Providing genetic counselling will become even more critical so that results of testing can be communicated to clients/couples in a manner in which they can understand. Eventually, the hope is that genetic counselling for males with infertility will include the incorporation of their genetic test result so that treatment is personalized and follows the precision medicine approach.

\section{Acknowledgments}

Funding: None.

\section{Footnote}

Provenance and Peer Review: This article was commissioned by the Guest Editors (Keith Jarvi and Jared Bieniek) for the series "Genetic Causes and Management of Male Infertility" published in Translational Andrology and Urology. The article has undergone external peer review.

Conflicts of Interest: All authors have completed the ICMJE uniform disclosure form (available at http:// dx.doi.org/10.21037/tau-2019-gcmi-09). The series "Genetic Causes and Management of Male Infertility" was commissioned by the editorial office without any funding or sponsorship. The authors have no other conflicts of interest to declare.

Ethical Statement: The authors are accountable for all aspects of the work in ensuring that questions related to the accuracy or integrity of any part of the work are appropriately investigated and resolved.

Open Access Statement: This is an Open Access article distributed in accordance with the Creative Commons Attribution-NonCommercial-NoDerivs 4.0 International License (CC BY-NC-ND 4.0), which permits the noncommercial replication and distribution of the article with the strict proviso that no changes or edits are made and the original work is properly cited (including links to both the formal publication through the relevant DOI and the license). See: https://creativecommons.org/licenses/by-nc-nd/4.0/.

\section{References}

1. Wilkes S, Chinn DJ, Murdoch A, et al. Epidemiology and 
management of infertility: a population-based study in UK primary care. Fam Pract 2009;26:269-74.

2. Flannigan R, Schlegel PN. Genetic diagnostics of male infertility in clinical practice. Best Pract Res Clin Obstet Gynaecol 2017;44:26-37.

3. Krausz C, Riera-Escamilla A. Genetics of male infertility. Nat Rev Urol 2018;15:369-84.

4. Feng HL. Molecular biology of male infertility. Arch Androl 2003;49:19-27.

5. Resta R, Biesecker BB, Bennett RL, et al. A new definition of Genetic Counselling: National Society of Genetic Counselors' Task Force report. J Genet Couns 2006;15:77-83.

6. Harper J. Preimplantation genetic diagnosis. 2nd edition. Cambridge: Cambridge University Press, 2009.

7. Liebaers I, Desmyttere S, Verpoest $W$, et al. Report on a consecutive series of 581 children born after blastomere biopsy for preimplantation genetic diagnosis. Hum Reprod 2010;25:275-82.

8. De Wert G, Dondorp W, Shenfield F, et al. ESHRE task force on ethics and Law22: preimplantation genetic diagnosis. Hum Reprod 2014;29:1610-7.

9. Helmes AW, Bowen DJ, Bengel J. Patient preferences of decision-making in the context of genetic testing for breast cancer risk. Genet Med 2002;4:150-7.

10. Knoppers BM, Strom C, Wright Clayton E, et al. ASHG statement. Professional disclosure of familial genetic information. The American Society of Human Genetics Social Issues Subcommittee on Familial Disclosure. Am J Hum Genet 1998;62:474-83.

11. Lacroix M, Nycum G, Godard B, et al. Should physicians warn patients' relatives of genetic risks? CMAJ 2008;178:593-5.

12. Weil J. Psychosocial genetic Counselling in the postnondirective era: a point of view. J Genet Couns 2003;12:199-211.

13. Nikolettos N, Asimakopoulos B, Hatzissabas I. Intrafamilial sperm donation: ethical questions and concerns. Hum Reprod 2003;18:933-6.

Cite this article as: Babul-Hirji R, Hirji R, Chitayat D. Genetic counselling for infertile men of known and unknown etiology. Transl Androl Urol 2021;10(3):1479-1485. doi: 10.21037/tau-2019-gcmi-09
14. McCarthy Veach P, LeRoy BS, et al. Facilitating the Genetic Counselling Process, A Practice Manual. New York: Springer-Verlag, 2003.

15. Baty BJ, Kinney AY, Ellis SM. Developing culturally sensitive cancer genetics communication aids for African Americans. Am J Med Genet A 2003;118A:146-55.

16. Fisher JR, Hammarberg K. Psychological and social aspects of infertility in men: an overview of the evidence and implications for psychologically informed clinical care and future research. Asian J Androl 2012;14:121-9.

17. Carmeli YS, Birenbaum-Carmeli D. The predicament of masculinity: Towards understanding the male's experience of infertility treatments. Sex Roles 1994;30:663-77.

18. van Balen F, Naaktgeboren N, Trimbos-Kemper TC. Invitro fertilization: the experience of treatment, pregnancy and delivery. Hum Reprod 1996;11:95-8.

19. Lotti F, Maggi M. Sexual dysfunction and male infertility. Nat Rev Urol 2018;15:287-307.

20. Gannon K, Glover L, Abel P. Masculinity, infertility, stigma and media reports. Soc Sci Med 2004;59:1169-75.

21. Lloyd M. Condemned to be meaningful: Non-response in studies of men and infertility. Sociol Health Illn 1996;18:433-54.

22. Miall CE. The stigma of involuntary childlessness. Social Problems 1986;33:268-82.

23. Throsby K, Gill R. 'It's different for men': masculinity and IV. Men Masc 2004;4:330-48.

24. Keylor R, Apfel R. Male infertility: Integrating an old psychoanalytic story with the research literature. Stud Gend Sex 2010;11:60-77.

25. Hinton L, Miller T. Mapping men's anticipations and experiences in the reproductive realm: (in)fertility journeys. Reprod Biomed Online 2013;27:244-52.

26. Mikkelsen AT, Madsen SA, Humaidan P. Psychological aspects of male fertility treatment. J Adv Nurs 2013;69:1977-86.

27. Wang HL, Wu B, Guo KM, et al. Psychological characteristics of and Counselling for carriers of structural chromosome abnormalities. Genet Mol Res 2016;15:1-10. 